\title{
Organização familiar no contexto da infância com paralisia cerebral: um estudo de caso
} Family organization in the context of the childhood with cerebral palsy: a case study

\author{
Larissa Tolentino Lôpo' • Ana Clara Pinheiro Andrade ${ }^{2} \bullet$ Ana Clara Rodrigues Marques ${ }^{3}$ Angelica Ruas Moreira $^{4}$ \\ Nilza Ferreira Tupiná Neta ${ }^{5}$ Andra Aparecida da Silva Dionízio ${ }^{6} \bullet$ Rosângela Barbos Chagas $^{7}$ \\ Maria Suely Fernandes Gusmão ${ }^{8}$ Ludmila Godinho Ribeiro $^{9}$ Patrick Leonardo Nogueira da Silva $^{10}$ \\ José Ronivon Fonseca"I
}

\begin{abstract}
RESUMO
Objetivo: avaliar a organização de uma família cadastrada em uma unidade de Estratégia Saúde da Família, para o cuidado de uma criança portadora de paralisia cerebral segundo o Modelo Calgary de Avaliação Familiar. Método: estudo de caso com abordagem qualitativa, realizado em um município do norte de Minas Gerais, durante abril e maio de 2019, por acadêmicas do curso de graduação em enfermagem, acompanhadas por enfermeiro especialista em saúde da família. $O$ sistema familiar foi descrito segundo o Modelo Calgary de Avaliação Familiar. Para avaliação da funcionalidade utilizou-se a escala Global Assessment of Relational Functioning. Para a coleta de dados, foi realizada uma entrevista semiestruturada durante uma visita domiciliar e leitura dos prontuários. Utilizou-se o software GenoPro® para confecção do genograma e ecomapa. Resultados: a família da paciente índice encontra-se simultaneamente nos seguintes estágios do ciclo de vida: família com filhos pequenos; família com crianças pré-escolares e família com crianças em idade escolar. Conclusão: a família estudada apresentou dificuldades de adaptação frente às demandas impostas pela condição de saúde da paciente índice.A desestruturação e a não adaptação às mudanças do sistema familiar interferiram na qualidade de vida de seus membros.
\end{abstract}

Palavras chave: Paralisia cerebral; Enfermagem domiciliar; Estratégia Saúde da Família.

\begin{abstract}
Objective: to evaluate the organization of a family registered in a Family Health Strategy unit, for the care of a child with cerebral palsy according to the Calgary Family Assessment Model. Method: case study with a qualitative approach, conducted in a municipality in the north of Minas Gerais, during April and May 2019, by undergraduate nursing students, accompanied by a family health specialist nurse. The family system was described according to the Calgary Family Assessment Model.To assess functionality, the Global Assessment of Relational Functioning scale was used. For data collection, a semi-structured interview was carried out during a home visit and reading of the medical records. The GenoPro® software was used to make the genogram and ecomap. Results: the family of the index patient is simultaneously in the following stages of the life cycle: family with young children; family with preschool children and family with school children. Conclusion: the family studied showed difficulties in adapting to the demands imposed by the health condition of the index patient. Destructuring and failure to adapt to changes in the family system interfered with the quality of life of its members.

Keywords: Cerebral Palsy; Home Health Nursing; Family Health Strategy.
\end{abstract}

NOTA

I Universidade Estadual de Montes Claros, Graduanda em Enfermagem. Montes Claros, Minas Gerais, Brasil. larissatolentinolopo@gmail.com

2 Universidade Estadual de Montes Claros, Graduanda em Enfermagem. Montes Claros, Minas Gerais, Brasil. anaaclara86@gmail.com

3 Universidade Estadual de Montes Claros, Graduanda em Enfermagem. Montes Claros, Minas Gerais, Brasil. anaclararmarques@gmail.com

4 Universidade Estadual de Montes Claros, Graduanda em Enfermagem. Montes Claros, Minas Gerais, Brasil. angelicaruas333@gmail.com

5 Universidade Estadual de Montes Claros, Graduanda em Enfermagem. Montes Claros, Minas Gerais, Brasil.nilzs0906@gmail.com

6 Enfermeira, Especialista em Saúde da Família pela Universidade Estadual de Montes Claros, Mestre em Ciência da Saúde pela Universidade Federal de São Paulo. Montes Claros, Minas Gerais, Brasil. andrabh@hotmail.com

7 Enfermeira, Especialista em Enfermagem de Saúde Pública pela Universidade Federal de Minas Gerais, Docente do curso de graduação em enfermagem da Universidade Estadual de Montes Claros. Montes Claros, Minas Gerais, Brasil. rosachagas@yahoo.com.br

8 Enfermeira, Referência técnica na Vigilância Epidemiológica do município de Montes Claros, Mestranda pelo Programa de Pós-Graduação em Cuidado Primário em Saúde da Universidade Estadual de Montes Claros (PPGCPS/UNIMONTES). Montes Claros, Minas Gerais, Brasil. suelyfergusmao@gmail.com

9 Médica, Residente em Medicina de Família e Comunidade pelo Hospital Universitário Clemente de Faria da Universidade Estadual de Montes Claros (HUCF/ UNIMONTES). Montes Claros, Minas Gerais, Brasil. ludmilagodinho28@gmail.com

10 Enfermeiro, Mestrando pelo Programa de Pós-Graduação em Cuidado Primário em Saúde da Universidade Estadual de Montes Claros (PPGCPS/UNIMONTES). Montes Claros, Minas Gerais, Brasil. patrick_mocesp70@hotmail.com

I I Enfermeiro, Mestre em Cuidado Primário em Saúde, Professor do Departamento de Enfermagem da Universidade Estadual de Montes Claros/UNIMONTES. Montes Claros, Minas Gerais, Brasil. jose.fonseca@unimontes.br 


\section{INTRODUÇÃO}

A família é responsável, em primeira instância, pela garantia da integralidade e promoção do cuidado de seus membros que, por sua vez, estão susceptíveis a diferentes perturbações, sejam elas internas ou externas ${ }^{(1)}$. As doenças crônicas são umas das principais formas de inquietações do sistema familiar, entre elas está a paralisia cerebral (PC) infantil. A PC é causada por uma lesão neurológica que afeta o cérebro durante o seu desenvolvimento no período gestacional ou até o segundo ano pós-natal, trata-se de uma doença crônica não progressiva responsável por causar limitações ao indivíduo(2-3). A criança afetada pode apresentar comprometimentos motores, cognitivos e sensoriais que prejudicam a sua qualidade de vida (QV) ${ }^{(4)}$.

Como cuidadora primária, famílias que possuem crianças portadoras de PC, em geral, enfrentam grande desgaste e sofrimento ${ }^{(3)}$.A partir do diagnóstico, o grupo familiar enfrentará um conjunto de emoções e conflitos que conferem a necessidade de adaptação ${ }^{(4)}$.Além das dificuldades emocionais, há também o aumento das despesas, já que famílias que possuem crianças que vivem com doenças crônicas possuem gastos três vezes maiores do que as famílias com crianças saudáveis ${ }^{(5)}$. Será preciso refazer metas e objetivos, pois esta reestruturação vem acompanhada da necessidade de compartilhar responsabilidades, medos e incertezas ${ }^{(6)}$.

As redes de apoio tornam-se então importantes orientadoras das condutas familiares ${ }^{(3)}$. A equipe de saúde é uma das principais composições dessa rede que, além de auxiliar no cuidado da criança, é responsável pelo bem-estar de toda a estrutura familiar. Explicitar tal processo, portanto, se torna necessário para a compreensão do contexto ao qual o grupo familiar está inserido, além de guiar profissionais da área na formulação de intervenções em situações semelhantes.

Neste sentido, o Modelo Calgary de Avaliação Familiar (MCAF) surge como um importante instrumento para a realização desse trabalho. Proposto por Wright e Leahey, pesquisadoras da Universidade de Calgary, no Canadá, ele permite a ampla compreensão do grupo estudado como um sistema, por meio dos diagnósticos de saúde, recursos e suportes disponíveis para o enfrentamento dos problemas ${ }^{(7)}$.

Esse modelo é composto por três categorias: a estrutural, a de desenvolvimento e a funcional. $\mathrm{Na}$ estrutural, são avaliadas a composição familiar, as relações internas e externas, e o contexto no qual a família está inserida; na categoria desenvolvimento, é contada a história familiar referente ao seu ciclo de vida; a funcional referese à interação entre os membros, seja ela instrumental, relacionada às atividades cotidianas, ou expressiva, que diz respeito às formas de comunicação e solução de pro- blemas $^{(8)}$.

A atenção domiciliar oferecida pela enfermagem é uma forma de intervenção que demanda qualificação profissional e competências específicas que se amparam em um conhecimento científico do campo de atuação, por meio dela é que se estabelece o vínculo entre a família e o meIhor trabalho junto à equipe multidisciplinar ${ }^{(9)}$. Ainda são poucos os estudos de avaliação familiar que servem como base de pesquisa aos profissionais de saúde da família e que possam auxiliá-los em seu processo de trabalho.

Diante disso, este estudo tem como objetivo avaliar a organização de uma família cadastrada em uma unidade de Estratégia Saúde da Família (ESF), para o cuidado de uma criança que vive com PC, segundo o MCAF.

\section{MÉTODO}

Artigo da monografia intitulada "Abordagem familiar como atividade prática da graduação de enfermagem da Unimontes", apresentado ao Departamento de Enfermagem da Universidade Estadual de Montes Claros/UNIMONTES. Montes Claros - MG, Brasil. 2018.

Trata-se de um estudo de caso com abordagem qualitativa, realizado durante abril e maio de 2019 , por acadêmicas do curso de graduação em enfermagem, acompanhadas por enfermeiro especialista em saúde da família em uma ESF localizada no município de Montes Claros, norte de Minas Gerais.

Como critério de escolha, optou-se por selecionar intencionalmente, a partir da análise de registros de prontuários físicos disponíveis na Unidade, uma família adscrita e cadastrada na ESF de abrangência, que vivencia mudanças na sua dinâmica com dificuldades de adaptação.A escolha dafamília deu-se pelo fato de a paciente-índice apresentar uma doença crônica, principal fator que gera a necessidade de reorganização familiar.

Foi enviada uma carta de apresentação e um Termo de Consentimento Institucional (TCl), juntamente com uma cópia do projeto de pesquisa, à Coordenação da Atenção Primária à Saúde (APS) da Secretaria Municipal de Saúde de Montes Claros (SMS/MOC) para autorização do estudo. $A$ instituição foi devidamente orientada quanto às diretrizes da pesquisa tendo a SMS/MOC assinado o TCI de modo a autorizar a realização do estudo. $A$ coleta de dados foi realizada no $1^{\circ}$ semestre de 2019 , durante os meses de abril e maio, pelo pesquisador responsável.

Para a coleta de dados, foi realizada uma entrevista semiestruturada durante a visita domiciliar (VD). As respostas foram convertidas em genograma e ecomapa, feitos por meio do software $G_{e n o P r o}{ }^{\circledR}$, que permite a criação de árvores genealógicas com representação de particularidades e interações entre os membros ${ }^{(10)}$.

O genograma é a representação gráfica que torna a dinâmica familiar mais evidente, de modo que, por meio 
deste instrumento foi possível avaliar as relações do grupo familiar ${ }^{(1)}$. Trata-se de uma árvore genealógica mais elaborada, pois nele se encontram pelo menos três gerações $^{(12)}$. Neste instrumento são utilizados formas e símbolos para registrar os problemas de saúde enfrentados por uma família, relações de conflito, data de nascimento (DN), dentre outras informações, onde se torna possivel observar marcos importantes para aquele grupo ${ }^{(13)}$.

O ecomapa trata-se de outra representação gráfica que expressa as relações da família com o seu ambiente ${ }^{(14)}$. É um desenho das interações familiares com a comunidade, seja dos lugares que mais frequentam por necessidade, vínculo ou onde recebem alguma forma de apoio. Ele auxilia o profissional de saúde na identificação das carências familiares, evidencia a falta de suportes como cultura e lazer, e de serviços essenciais como saúde e educação(13).

O sistema familiar foi descrito de acordo com o MCAF. O método considera a avaliação familiar em três dimensões: (I) a estrutural; (2) a de desenvolvimento; e (3) a funcional, já abordadas neste estudo. Para a identificação do ciclo de vida no qual a família se encontra, foi utilizada a classificação de Chapadeiro, Andrade e Araújo(15) que o divide nos seguintes estágios: (I) jovens adultos solteiros saindo de casa; (2) união no casamento: a nova família; (3) famílias com filhos pequenos, que inclui família com crianças pré-escolares e família com criança em idade escolar; (4) famílias com filhos adolescentes; (5) lançando os filhos e seguindo em frente; e (6) famílias no estágio tardio de vida.

Para avaliação da funcionalidade, utilizou-se a escala Global Assessment of Relational Functioning (GARF). Ela descreve diversas situações e permite ao avaliador dar uma nota global de I a 99, ou seja, quanto maior a nota, melhor é a funcionalidade. Considera-se grupo de alto risco aquele com pontuação $\leq 50$; de risco moderado, entre $5 \mathrm{I}$ e 80 ; e de baixo risco, $\geq 8 \mathrm{I}^{(16)}$.

As representações da família e de seus respectivos membros possuem ícones padronizados e legenda própria. Para garantir a privacidade, $\mathrm{o}$ sigilo e $\mathrm{o}$ anonimato de todos os membros, foram utilizados pseudônimos (nomes fictícios) para representar graficamente cada membro da família, sendo estes: “João", "Osvaldo", “Lourdes”, "Hugo", e "Maria” (representação da família paterna);“José”,"“Henrique”,"Ana Catarina”, "Paulo", “Nicolas”, “Danilo", "Pablo” e "Rosa” (representação da família materna); "Rogério", "Helena" (paciente-índice), "Vanda”, “Sofia”, “Tony”, “Camila”, “Enzo”, "Pedro" e "Greice" (representação da família principal). Os participantes foram devidamente orientados quanto às diretrizes do estudo de modo a assinarem voluntariamente o Termo de Consentimento Livre e Esclarecido (TCLE) o qual foi emitido em duas vias, sendo uma para o familiar responsável, e outra para a equipe de pesquisa.

Foram respeitados os preceitos éticos estabelecidos pela Resolução ${ }^{\circ}$ 510, de 7 de abril de 2016, do Conselho Nacional de Saúde (CNS) o qual regulamenta a realização da pesquisa envolvendo seres humanos ${ }^{(17)}$. O projeto de pesquisa foi apreciado e aprovado pelo Comitê de Ética em Pesquisa da Universidade Estadual de Montes Claros (CEP UNIMONTES), sob parecer consubstanciado $n^{\circ} 2.896 .761 / 2018$, Certificado de Apresentação para Apreciação Ética (CAAE) n 976389 |8.0.0000.5 I 46.

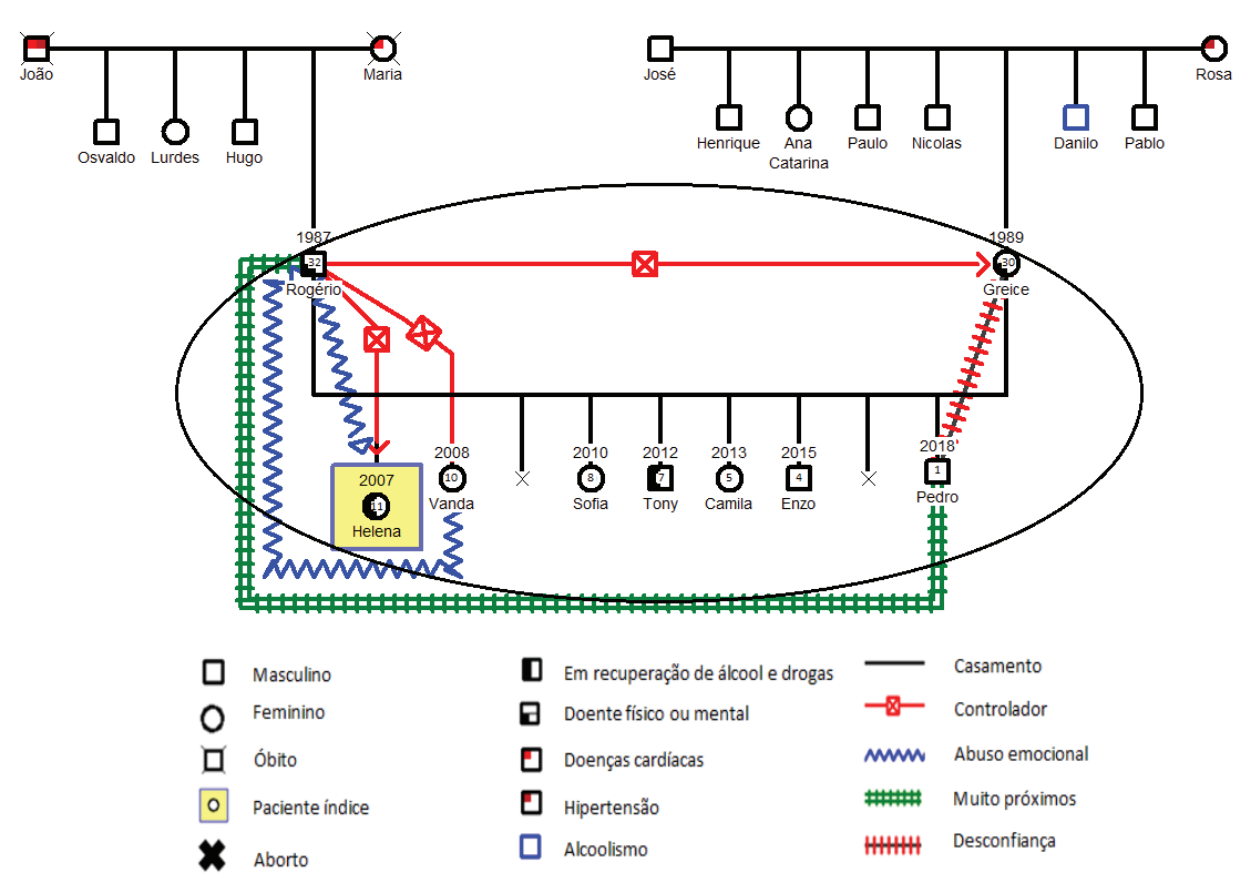

FIGURA 1 - Representação gráfica da composição e relações familiares por meio do genograma. Montes Claros, Minas Gerais, Brasil, 2019.

Fonte: Acervo próprio, 2019. 


\section{RESULTADOS}

Seguindo o MCAF, avaliou-se a família em todas as suas dimensões, sendo estas: estrutural, de desenvolvimento e funcional.

\section{Avaliação Estrutural}

Para a avaliação estrutural da família abordada, utilizou-se o genograma (Figura I) e ecomapa (Figura 2).

A paciente-índice, "Helena", tem II anos de idade, é natural do município de Montes Claros, norte de Minas Gerais, e vive com PC. Reside com os pais e seis irmãos mais novos, sendo estes compostos por três meninas e três meninos de $10,9,7,6,4$ e I anos, em uma casa de dois cômodos cedida por um centro de convívio frequentado pela família.

Conforme a figura I, as relações são, em geral, fracas e prejudiciais. É perceptível um atrito entre pai e filhas mais velhas. A relação do pai com a mãe tende a ser controladora, tendo ele uma relação de afeto apenas com o filho mais novo, "Pedro", de quem a mãe possui dúvidas sobre a paternidade. Já a relação entre os irmãos é, no geral, amigável.

Como observado na figura 2 , a família relata ter um forte vínculo com a igreja, segundo os pais "Rogério" e "Greice", por meio dela foi alcançada a recuperação de ambos da dependência química. Cabe ressaltar que apesar do relato dos pais, profissionais de saúde da ESF e vizinhos relatam que os mesmos ainda fazem uso de drogas ilícitas. Ademais, a igreja é uma fonte de ajuda finan- ceira necessária oferecida por outros frequentadores, uma vez que os pais são desempregados, a mãe é dona de casa e o pai realiza trabalhos informais esporadicamente. A principal fonte de renda da família é advinda do auxílio governamental Bolsa Família.

Outro ponto de apoio é o centro de convívio do bairro, onde a mãe leva o filho mais novo "Pedro" para brincar e o qual cedeu a casa onde a família vive evidenciando, portanto, uma forte relação da família com esta instituição. Por outro lado, a relação com a ESF é fraca. Além de "Helena", outros filhos do casal necessitam de cuidados clínicos específicos, sendo "Tony" devido a ataques convulsivos e "Enzo" por ser portador de fibrose cística. Entretanto, nenhum dos pais leva as crianças com a freqüência necessária à Unidade Básica de Saúde (UBS) para acompanhamento e nem se dispõem a buscar a medicação prescrita, além de demonstrar resistência quando o enfermeiro responsável faz aconselhamentos sobre a situação familiar.

Quanto a relação com a escola, também fraca, a família mora longe e as crianças dependem do transporte público. Em dias de chuva faltam devido à impossibilidade de chegar ao ponto de ônibus, além disso, foi relatado que apresentam dificuldade de aprendizagem e os pais não se envolvem na educação escolar.

Referente à família extensa, foi identificada relação moderada, visto que as crianças visitam a casa da avó materna em alguns fins de semana.A mãe possui uma forte relação com a vizinha que é para ela uma confidente.

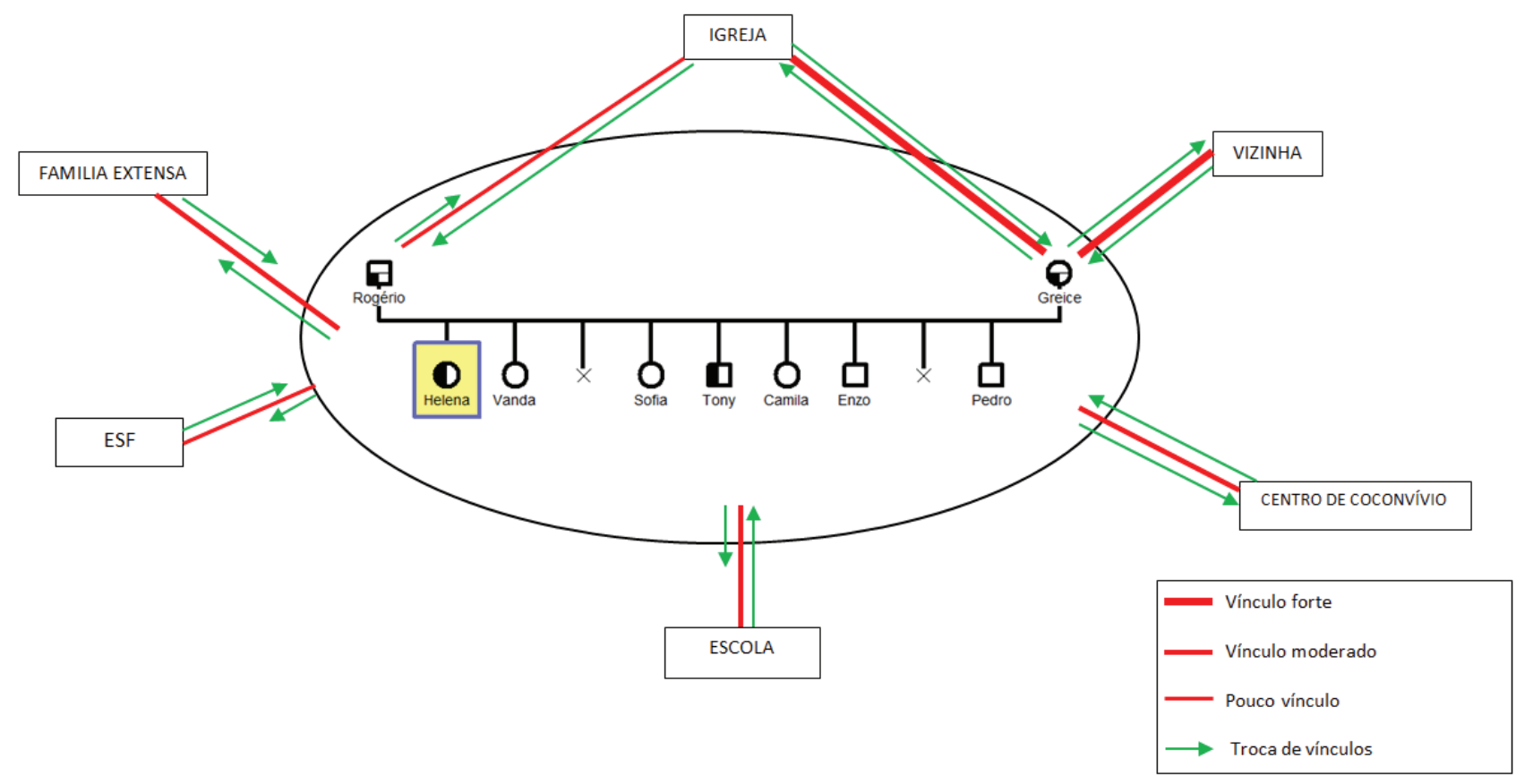

FIGURA 2 - Representação gráfica das relações externas da família por meio do ecomapa. Montes Claros, Minas Gerais, Brasil, 2019.

Fonte: Acervo próprio, 2019. 
Em relação ao contexto ambiental, a família reside em um bairro localizado na área periférica da cidade. Em frente à casa há presença de um esgoto à céu aberto, além da região ter um histórico de tráfico de drogas. As ruas não são pavimentadas, e há muitos lotes vagos.

\section{Avaliação de desenvolvimento}

A família da paciente índice encontra-se de forma simultânea nos seguintes estágios do ciclo de vida: família com filhos pequenos; família com crianças pré-escolares e família com criança em idade escolar ${ }^{(18)}$. As tarefas propostas para cada ciclo não são cumpridas, o que prejudica o desenvolvimento familiar. O comportamento dos pais demonstra-se muito exigente e pouco responsivo, controlador e com pouca atenção e comunicação, caracterizado segundo Chapadeiro, Andrade e Araújo (15), como prática educativa autoritária. Os filhos tendem a ser muito obedientes às regras e ter autoconfiança limitada, características observadas nas crianças da família, em especial as mais velhas. Nota-se o sentimento de medo por parte das crianças em relação ao pai.

\section{Avaliação funcional}

Utilizou-se a escala GARF para avaliar o funcionamento familiar. De acordo com esta escala, a família foi classificada como alto risco, com 15 pontos.

\section{DISCUSSÃO}

Ao trabalhar com uma família, é fator primordial para o profissional de saúde o entendimento do modo de organização familiar, incluindo seus valores, crenças e procedimentos cotidianos ${ }^{(19)}$. A família recebe grande apoio social da igreja e do centro de convívio que frequenta.As redes de apoio social são significativas fontes de orientação quanto aos sentimentos e atitudes tomadas pelo grupo $^{(3)}$. O forte vínculo das famílias com pessoas e instituições relevantes representam recursos protetivos para seus membros ${ }^{(20)}$.

No entanto, em situações de adoecimento, a família é considerada a principal unidade responsável pelo cuidado do integrante enfermo, todavia pode haver hesitação frente ao estresse advindo do cuidado com doentes crônicos ${ }^{(21)}$. Crianças com PC demandam cuidados especiais e dedicação, é preciso que a família se reestruture para garantir um desenvolvimento adequado a esses indivíduos ${ }^{(2)}$.

No processo de desenvolvimento, também é necessário que haja atenção e participação na educação infantil. Quando os responsáveis oferecem pouco ou nenhum apoio afetivo aos filhos e não demonstram envolvimento com as atividades por eles realizadas é provável que as crianças tenham um baixo desempenho escolar ${ }^{(22)}$. Fatores como instabilidade nos papéis da família, estresse familiar e uma relação fraca entre os pais e os filhos também são empecilhos no desenvolvimento das crianças ${ }^{(23)}$.

A PC causa limitação cognitiva ${ }^{(4)}$. $O$ fato de "Helena" ter $\mathrm{PC}$ pode ser para a mesma um dificultador em seu processo de aprendizagem. Apesar de o local e a dimensão da lesão neurológica serem determinantes no prognóstico da criança, independente do nível da paralisia, o estímulo físico e cognitivo e o cuidado prestado pela família também são determinantes para o seu desenvolvimento e melhoria da QV(24).

Quanto à família extensa, foi identificada relação moderada, visto que as crianças visitam a casa da avó materna em alguns fins de semana. $O$ auxílio da família nos cuidados com as crianças é aceitável, desde que não haja interferência no modo de educação escolhido pelos pais. Entretanto, no presente caso, a interferência da família extensa pode ser um fator positivo, que auxiliará na educação e sustento das crianças, já que os pais se mostram negligentes no cuidado com as mesmas ${ }^{(15)}$.

Outro fator preocupante em relação saúde da família é o contexto ambiental em que vivem. A falta de saneamento básico atinge as populações mais carentes localizadas em bairros pobres e periféricos da zona urbana, trata-se de um importante meio de veiculação de doenças que traz prejuízos à QV da população(25-26).

No que diz respeito ao desenvolvimento, a família do estudo está nas seguintes fases: família com filhos pequenos; família com crianças pré-escolares e família com criança em idade escolar ${ }^{(18)}$. A mudança dos ciclos de vida é marcada por acontecimentos importantes que transformam a estrutura familiar com novas tarefas a serem cumpridas em cada etapa, e o descumprimento dessas pode comprometer o seu funcionamento(15).

As tarefas do estágio família com filhos pequenos são: garantia de espaço para o nascimento da criança, isto é, os pais devem ter disponibilidade emocional e física; acoIhimento, cuidado, educação e aproximação da família extensa com o nascimento ${ }^{(15)}$. Dentre as tarefas do estágio "Família com Crianças Pré-Escolares" estão: enfrentar os custos financeiros da vida familiar e assumir o papel maduro apropriado à família que cresce ${ }^{(18)}$. No estágio "Família com Criança em Idade Escolar", as tarefas a serem desempenhadas pelos pais incluem: facilitar a transição da casa para a escola e lidar com as crescentes demandas de tempo e dinheiro ${ }^{(15,18)}$.

As tarefas do estágio "Família com Filhos Pequenos" são: garantia de espaço para o nascimento da criança, isto é, os pais devem ter disponibilidade emocional e física; acolhimento, cuidado, educação e aproximação da família extensa com o nascimento ${ }^{(15)}$. Observa-se que nessa família não houve garantia de espaço emocional para receber as crianças, visto que, as mesmas não recebem demonstrações de afeto dos pais. Tam- 
bém não foi garantido o espaço físico adequado, sendo que a casa em que residem conta com instalações precárias, apresentando até mesmo ausência de um banheiro, por isso a família faz uso de fossa. As crianças não possuem um quarto para dormir e contam apenas com um colchão instalado na sala, o qual se encontra em péssimas condições de higiene.

Dentre as tarefas do estágio "Família com Crianças Pré-Escolares" estão: enfrentar os custos financeiros da vida familiar e assumir o papel maduro apropriado à família que cresce ${ }^{(18)}$. Percebe-se que os pais não se prepararam ou se estabilizaram financeiramente para lidar com os gastos de uma vida em família, visto que não possuem uma renda fixa, necessitam de ajuda financeira e contam com doações de instituições e pessoas próximas. Evidencia-se que não há o desempenho dos papéis ideais necessários para o desenvolvimento e vivência confortável da família e seus integrantes.

No estágio "Família com Criança em Idade Escolar", as tarefas a serem desempenhadas pelos pais incluem: facilitar a transição da casa para a escola e lidar com as crescentes demandas de tempo e dinheiro ${ }^{(15,18)}$. Mediante avaliação da família é possível identificar que os pais mostram-se distantes da vida escolar dos filhos, não lhes oferecendo apoio no momento da transição casa-escola ou não participando do acompanhamento do desempenho escolar dos mesmos.

A PC pode ocasionar prejuízos no desenvolvimento de atividades da vida diária (AVD), que demandam uma assistência continuada, dessa forma, necessidades como alimentação, estimulação, atenção e afeto, são cuidados importantes para crianças que apresentam essa condição como parte de seu crescimento e desenvolvimento ${ }^{(27)}$. Durante o estudo da família foi identificado que os pais não proporcionam à paciente índice e aos outros filhos esses cuidados mínimos. Além disso, a criança com PC precisa de acompanhamento médico contínuo, recomendação que não é seguida pelos pais.

Em relação à funcionalidade, a família foi classificada de acordo com a escala GARF em alto risco. Nos sistemas familiares disfuncionais os membros, neste caso os pais, não se comprometem com a realização de tarefas para um bom funcionamento do grupo, há priorização dos interesses individuais em detrimento do resto da família e uma não representação dos seus papéis dentro do sistema. Os vínculos afetivos tornam-se superficiais e instáveis, pode haver comportamento agressivo e hostil entre os membros, mesmo que não demonstrados abertamente ${ }^{(28)}$.

Nesse cenário, é preciso que haja uma reorganização familiar, em que os membros desempenhem tarefas de acordo com seus papéis, de modo que seja proporcionado o funcionamento adequado e harmonioso do sistema familiar em qualquer situação(21). $O$ enfermeiro é um dos profissionais responsáveis pelo cuidado integral da família. Por meio da sua atuação é possível traçar metas e planos de cuidados que objetivem o desenvolvimento de todos os membros do grupo, a minimização da instabilidade nos papéis e a ampliação das relações familiares ${ }^{(6)}$.

\section{CONSIDERAÇÕES FINAIS}

A família estudada apresentou dificuldades de adaptação frente às demandas impostas pela condição de saúde da paciente-índice. As tarefas do ciclo de vida não estão sendo cumpridas e a relação entre os membros mostrou-se conflituosa, o que dificulta o desenvolvimento e QV das crianças, em especial de "Helena", que não possui suas exigências de cuidados especiais atendidas. Apesar de ser evidente a necessidade de uma reestruturação, a família apresenta grande resistência às intervenções propostas pelos profissionais da ESF. Uma assistência contínua deve ser prestada ao grupo, em especial aos filhos. Para tanto, a equipe de saúde deve se unir à família extensa, escola e outras instituições próximas para a formação de uma rede de apoio capaz de assegurar o cumprimento das intervenções propostas.

A utilização do MCAF viabilizou ao profissional responsável pela assistência familiar o conhecimento da sua dinâmica, além da identificação das necessidades vivenciadas e a formulação de estratégias de cuidado e enfrentamento.A desestruturação e a não adaptação às mudanças do sistema familiar interferiu diretamente na QV de seus membros.

$O$ presente estudo pode ser utilizado como referencial teórico em pesquisas científicas, além de auxiliar profissionais de saúde na sua atuação. Ademais, atua como um incentivo à maior utilização de tecnologias em saúde, como o GenoPro ${ }^{\circledR}$ e escalas de avaliação de funcionalidade familiar, que facilitem o processo terapêutico a partir da compreensão do contexto em que vive o paciente.

Como limitação, deste estudo destaca-se a impossibilidade de generalização devido a abordagem de apenas um caso, além da escassez de pesquisas recentes referentes à saúde da família que pudessem servir como referencial teórico para a discussão apresentada. 


\section{REFERÊNCIAS}

I. Nishimoto CLJ, Duarte ED. Family organization for the care of children with chronic conditions, discharged from the neonatal intensive care unit. Texto contexto - enferm. [Internet]. 2014 [cited 2020 Sept 18];23(2):318-27. Available from: https://doi.org/I0.1590/0104-07072014001330013

2. Silva SSC, Pontes FAR. Families of children with cerebral palsy routine. Educ. rev. [Internet]. 2016 [cited 2020 Sept 18];32(59):65-78. Available from: https://doi. org/10.1590/0104-4060.44688

3. Polita NB, Tacla MTGM. Rede e apoio social às famílias de crianças com paralisia cerebral. Esc. Anna Nery [Internet]. 2014 [cited 2020 Sept I4];|8(I):75-8I. Available from: https://doi.org/|0.5935/|4|4-8|45.20|400 I I

4. Afonso T, Ramos MFH, França IL, Pontes FAR, Silva SSC. Cuidado parental à criança com paralisia cerebral: uma revisão sistemática da literatura. Rev. bras. educ. espec. [Internet]. 2016 [cited 2020 Sept 13];22(3):455-70. Available from: https://doi.org/ I0.1590/S I4 I3-653822 I60003000 I I

5. Baltor MRR, Dupas G. Experiences from families of children with cerebral paralysis in context of social vulnerability. Rev. Latino-Am. Enferm. [Internet]. 2013 [cited 2020 Sept I3];2I(4):956-63. Available from: https://doi.org/10.1590/ S0104-II692013000400018

6. Dezoti AP, Alexandre AMC, Freire MHS, Mercês NNA, Mazza VA. Apoio social a famílias de crianças com paralisia cerebral. Acta paul. enferm. [Internet]. 2015 [cited 2020 Sept 13];28(2):172-6. Available from: https://doi. org/l0.1590/1982-0194201500029

7. Souza TCF, Melo AB, Costa CML, Carvalho JN. Calgary model of family evaluation: evaluation of families with individuals sickened with tuberculosis. Enferm. Foco [Internet]. 2017 [cited 2020 Sept 13];8(I): 17-2I. Available from: http://revista.cofen.gov.br/index.php/enfermagem/article/ view/927

8. Silva L, Bousso RS, Galera SAF.The use of the Calgary Model for assessment of families of the aged in clinical practice. Rev. bras. enferm. [Internet]. 2009 [cited 2020 Sept 16];62(4):530-4. Available from: https://doi.org/I0.1590/ S0034-71672009000400006

9. Andrade AM, Silva KL, Seixas CT, Braga PP. Atuação do enfermeiro na atenção domiciliar: uma revisão integrativa da literatura. Rev. bras. enferm. [Internet]. 2017 [cited 2020 Sept 12];70(1):210-9. Available from: https://doi. org/10.1590/0034-7|67-2016-02/4

10. GenoPro [homepage in internet]. What is the GenoPro? [cited 2020 Oct 12]. Available from: https://genopro.com/

I I. Barreto M, Crepaldi MA. Genogram in context of SUS and SUAS from a case study. Nova perspect. sist. [Internet]. 2017 [cited 2020 Sept 13];26(58):74-85. Available from: http://pepsic.bvsalud.org/scielo.php?script=sci_arttext\&pi$\mathrm{d}=\mathrm{SO}$ I 04-784 I 2017000200006

12. Borges CD, Costa MM, Faria JG. Genogram and primary health care: in search of integrality. Rev. Psicol. Saúde [Internet]. 20 I 5 [cited 2020 Sept 18];7(2): I33-4I.Available from: http://pepsic.bvsalud.org/pdf/rpsaude/v7n2/v7n2a07.pdf

13. Nascimento LC, Dantas IRO, Andrade RD, Mello DF. Genogram and ecomap: brazilian nursing contributions. Texto contexto - enferm. [Internet]. 2014 [cited 2020 Sept I8];23(I):2 I I-20. Available from: http://dx.doi.org/ I0.1590/ SOI04-070720I4000I00025

14. Souza IP, Bellato R, Araújo LFS, Almeida KBB. Genograma e ecomapa como ferramentas para compreensão do cuidado familiar no adoecimento crônico de jovem. Texto contexto - enferm. [Internet]. 2016 [cited 2020 Sept 14];25(4):el5300I5. Available from: https://doi. org/10.1590/0104-070720160015300I5

15. Chapadeiro CA, Andrade HYSO, Araújo MRN. A família como foco da Atenção Primária à Saúde [Internet]. Belo Horizonte (MG): NESCON/UFMG, 201 I [cited 2020 Sept 13]. Available from: https://www.nescon.medicina.ufmg.br/ biblioteca/imagem/2726.pdf

16. Falceto OG, Busnello ED, Bozzetti MC.Validação de escalas diagnósticas do funcionamento familiar para utilização em serviços de atenção primária à saúde. Rev. Panam. Salud Publica [Internet]. 2000 [cited 2020 Sept I3];7(4):255-63. Disponível em: https://www.scielosp.org/pdf/rpsp/2000. v7n4/255-263/pt

17. Brasil. Ministério da Saúde. Conselho Nacional de Saúde. Resolução $n^{\circ} 510$, de 7 de abril de 2016 [Internet]. Regulamenta a realização de pesquisas envolvendo seres humanos e dá outras providências. Brasília: MS, 2016 [cited 2020 Oct 12]. Available from: http://conselho.saude.gov.br/resolucoes/2016/Reso510.pdf

18. Minas Gerais. Implantação do Plano Diretor da Atenção Primária à Saúde - Oficina 6: abordagem familiar [Internet]. Belo Horizonte (MG): Escola de Saúde Pública do Estado de Minas Gerais, 2010 [cited 2020 Sept I3]. Available from: https://www.nescon.medicina.ufmg.br/biblioteca/imagem/272I.pdf

19. Cavalcante AES, Rodrigues ARM, Paiva GM, Mourão Netto JJ, Goyanna NF. Calgary model implementation of family assessment in family health strategy. Enferm. Bras. [Internet]. 2017 [cited 2020 Sept 13];16(2):105-14. Available from: http://www.portalatlanticaeditora.com.br/index.php/enfermagembrasil/article/view/998/20I 2

20. Seibel BL, Falceto OG, Hollist CS, Spinger P, Fernandes CLC, Koller SH. Social support and family functioning: longitudinal study of vulnerable families. Pensando fam. [Internet] 2017 [cited $2020 \mathrm{Sep}$ I3];2 I ( ): I 20-36.Available from: http://pepsic.bvsalud.org/pdf/penf/v2 In I/v2 In la I0.pdf

2I. Santos AL, Cecílio HPM, Teston EF, Marcon SS. Conhecendo a funcionalidade familiar sob a ótica do doente crônico. Texto contexto - enferm. [Internet]. 2012 [cited 2020 Sept I4];2 I (4):879-86. Available from: http://dx.doi.org/ / 0.1590/ SOI04-070720I 2000400019 
22. Magdalena SM.The effects of parental influences and school readiness of the child. Procedia - Soc. Behavioral Sci. [Internet]. 2014 [cited 2020 Sept I3]; I27:733-7. Available from: https://doi.org/10.1016/j.sbspro.2014.03.345

23. Cia F, Barham EJ, Fontaine AMGV. Desempenho acadêmico e autoconceito de escolares: contribuições do envolvimento paterno. Estud. psicol. (Campinas) [Internet]. 2012 [cited 2020 Sept 13];29(4):46I-70. Available from: https://www. scielo.br/pdf/estpsi/v29n4/v29n4a0I.pdf

24. Milbrath VM, Siqueira HCH, Motta MGC, Amestoy SC. Família da criança com paralisia cerebral: percepção sobre as orientações da equipe de saúde. Texto contexto - enferm. [Internet]. 2012 [citado 2020 Sept I 4];2 I (4):92 I-8.Available from: https://doi.org/ I0.1590/S0 I04-070720 I 2000400024

25. Sousa ACA, Gomes JP. Desafios para o investimento público em saneamento no Brasil. Saúde debate [Internet]. 2019 [cited 2020 Sept 18];43(esp):36-49. Available from: https:// doi.org/10.1590/0103-I1042019s703
26. Damke T, Pasini F.The importance of water potability in basic sanitation for public health promotion in Brazil. Rev. Eletr. Teccen [Internet]. 2020 [cited 2020 Sept I8]; I3(I):8-I5. Available from: https://doi.org//0.2 I727/teccen.v I3il.2200

27. Simões CC, Silva L, Santos MR, Misko MD, Bousso RS. A experiência dos pais no cuidado dos filhos com paralisia cerebral. Rev. Eletr. Enf. [Internet]. 2013 [cited 2020 Sept I4];।5(I):| 38-45. Available from: https://doi.org/10.52/6/ ree.vI5il.13464

28. Brasil. Ministério da Saúde. Secretaria de Atenção à Saúde. Departamento de Atenção Básica. Envelhecimento e saúde da pessoa idosa [Internet]. Brasília (DF): MS, 2007 [cited 2020 Sept 13]. 192p. Available from: https://www.saude.sc. gov.br/index.php/documentos/atencao-basica/saude-da-pessoa-idosa/656 I-caderno-de-atencao-basica-pessoa-idosa/file

Recebido: 2020-09-21

Aceito: $2020-10-22$ 